\title{
Erratum to: Examining influencing factors of post-adoption usage of mobile internet: Focus on the user perception of supplier-side attributes
}

\author{
Young Mee Shin • Seung Chang Lee • Bongsik Shin •
}

Ho Geun Lee

Published online: 20 October 2009

(C) Springer Science + Business Media, LLC 2009

\section{Erratum to: Inf Syst Front}

DOI 10.1007/s10796-009-9184-x

The following acknowledgments should have been included in the original version of this article:

Acknowledgements This research is supported by the Ubiquitous Computing and Network(UCN) Project, Knowledge and Economy Frontier R\&D Program of the Ministry of Knowledge Economy(MKE) in Korea and a result of subproject UCN 09C1-T2-30S.

We apologize for this unfortunate omission.

The online version of the original article can be found at http://dx.doi. org/10.1007/s10796-009-9184-x.

Y. M. Shin · H. G. Lee

School of Business, Yonsei University,

Seoul, Korea

Y. M. Shin

e-mail: ymshin1009@lycos.co.kr

H. G. Lee

e-mail: h.lee@yonsei.ac.kr

S. C. Lee

Small Business Corporation,

Seoul, Korea

e-mail: lee_seungchang@yonsei.ac.kr

B. Shin $(\bowtie)$

Information and Decision Systems,

College of Business Administration, San Diego State University,

5500 Campanile Drive,

San Diego, CA 92182, USA

e-mail: bshin@mail.sdsu.edu 